\title{
Structure of the Passive Film formed on Fe-Mn-Si-Cr-Ni Shape Memory Alloy after Wet and Dry Corrosion Test
}

\author{
T. Nishimura \\ National Institute for Materials Science (NIMS), Tsukuba 305-0047, Japan
}

\begin{abstract}
The corrosion resistance of an Fe-Mn-Si-Cr-Ni shape memory (16 Mn) alloy was estimated by the wet and dry corrosion tests, and the structure of the passive film formed on the alloy was examined by primary EELS (Electron Energy Loss Spectroscopy) using TEM (Transmission Electron Microscopy) analysis. The electrochemical behavior of $16 \mathrm{Mn}$ alloy was investigated by EIS (Electrochemical Impedance Spectroscopy). $16 \mathrm{Mn}$ alloy showed much higher corrosion resistance than the carbon steel (SM) in wet and dry corrosion tests. In EIS measurement following corrosion test, $16 \mathrm{Mn}$ alloy had much larger value of corrosion resistance $\left(Z_{1 \mathrm{mHz}}\right)$ by forming the passive film as compared to SM. In AES (Auger Electron Spectroscopy) and XPS (X-ray Photoelectron Spectroscopy) analysis, the passive film of 16 Mn alloy was shown to contain $\mathrm{Fe}, \mathrm{Mn}, \mathrm{Cr}, \mathrm{Si}$ and Ni. From TEM-EELS, the passive film was found to consist of 2 layers of a Cr-Si-rich in inner and an Mn-rich outer layer of Fe oxide. It was found that $16 \mathrm{Mn}$ alloy could maintain the passive film which composed of effective elements in the wet and dry environment. [doi:10.2320/matertrans.M2014029]
\end{abstract}

(Received January 22, 2014; Accepted March 27, 2014; Published May 16, 2014)

Keywords: shape memory alloy, corrosion, transmission electron microscopy, electrochemical impedance spectroscopy

\section{Introduction}

The shape memory effect has been found in $\mathrm{Au}-\mathrm{Cd}, \mathrm{Ti}-\mathrm{Ni}$, $\mathrm{Cu}-\mathrm{Zn}-\mathrm{Al}$ and several other alloy systems. ${ }^{1-3)}$ Among them, Iron base alloys have attentions because of reduced material cost. Recently, an Fe-Mn-Si base shape memory alloy has been reported by A. Sato et al., and showed the excellent mechanical property. ${ }^{4,5)}$ However, there are few papers which deal with corrosion resistance of this type of the iron-base shape memory alloy. ${ }^{6}$ H. Fukai et al. investigated the oxidation resistance of an $\mathrm{Fe}-\mathrm{Mn}-\mathrm{Si}-\mathrm{Cr}$ base shape memory alloy using primarily EPMA (Electron Probe Micro Analyzer) and XPS, and found high effect of $\mathrm{Cr}$ on the oxidation resistance. ${ }^{7)}$

In order to identify the atmospheric corrosion resistance of this alloy, it is important to conduct the wet and dry corrosion test containing chloride solution. ${ }^{8)}$ Generally, this type of alloy makes the passive film in the atmospheric environment. As the passive film was very thin $(\sim n m)$, nano structure of the film was investigated by using TEM in this study. The passive film formed in the wet and dry test was cut using FIB (Focused Ion Beam), and the chemical state of each element was investigated by EELS. ${ }^{9}$ EIS was employed for the samples following the wet and dry test to investigate the electrochemical behavior of an $\mathrm{Fe}-\mathrm{Mn}-\mathrm{Si}-\mathrm{Cr}$ base shape memory alloy. ${ }^{8)}$

\section{Experimental Procedure}

\subsection{Wet and dry cyclic corrosion test and samples}

The corrosion test consisted of (1) wetting sample surfaces with $0.4 \mathrm{~L}$ of a 0.5 mass $\% \mathrm{NaCl}$ solution in $1 \mathrm{~m}^{2}$, and (2) drying the sample in a chamber maintained at 25 degree $\mathrm{C}$, $60 \% \mathrm{RH}$ for $12 \mathrm{~h} .{ }^{8)}$ Immediately before dropping a solution, the sample was washed in distilled water and dried to prevent progressive salt accumulation. The sample material (16 Mn alloy) was an $\mathrm{Fe}-16 \% \mathrm{Mn}-12 \% \mathrm{Cr}-5 \% \mathrm{Si}-5 \% \mathrm{Ni}$ (mass $\%$ ) shape memory alloy. As a basis for comparison, the carbon steel (SM) was used in this study.

\subsection{Physical analysis of the passive film on 16 Mn shape memory alloy}

AES (Auger Electron Spectroscopy) and XPS (X-ray Photo electron Spectroscopy) were employed for the surface analysis of the sample of $16 \mathrm{Mn}$ alloy. AES was performed with an accelerate voltage of $5 \mathrm{kV}$, a sample current of $0.1 \mu \mathrm{A}$, an experimental region of $10 \times 10 \mu \mathrm{m}$, a slope angle of 30 degree for the sample. In the case of the depth profile acquired by ASE, Argon spatter was used with a voltage of $2 \mathrm{kV}$, and a rate of $1 \mathrm{~nm} / \mathrm{min}$. XPS spectra were acquired by Al $\mathrm{K} \alpha$ of $600 \mu \mathrm{m} \varphi$ for the sample of $16 \mathrm{Mn}$ alloy with a takeoff angle of 30, 60 and 90 degrees.

In order to investigate the surface (passive) film at the nano level, TEM was employed for the sample of $16 \mathrm{Mn}$ alloy. After the sample was mounted in resin, it was mirror-polished using emery paper and diamond paste. The passive film of 16 Mn alloy was cut by FIB (focused ion beam) from the above sample using SEM. A depth profile of elements for the passive film of the sample was examined by EDXS (Energy dispersing $\mathrm{X}$-ray)-TEM analysis with a beam of $0.2 \mathrm{~nm}$ in the area of $5 \times 8 \mathrm{~nm}$. The concentrations of $\mathrm{Fe}, \mathrm{Mn}, \mathrm{Cr}, \mathrm{Si}$ and $\mathrm{Ni}$ in the passive film were measured for the $16 \mathrm{Mn}$ alloy. EELS-TEM analysis was carried out to examine the chemical state of Fe, $\mathrm{Mn}, \mathrm{Cr}, \mathrm{Si}, \mathrm{Ni}$ and Oxygen in the passive film of $16 \mathrm{Mn}$ alloy.

\subsection{EIS measurement}

After the corrosion test, electrodes were fabricated out of $16 \mathrm{Mn}$ alloy. Then, EIS measurements were performed in $0.1 \mathrm{M} \mathrm{Na}_{2} \mathrm{SO}_{4}$ solution using a 2-electrode system with a measurement frequency range of $20 \mathrm{kHz}$ to $1.0 \mathrm{mHz}$ and an applied voltage of $10 \mathrm{mV}$.

\section{Results and Considerations}

\subsection{Corrosion resistance of $16 \mathrm{Mn}$ shape memory alloy}

The corrosion resistance of the $\mathrm{Fe}-\mathrm{Mn}-\mathrm{Si}-\mathrm{Cr}-\mathrm{Ni}$ shape memory alloy (16Mn alloy) was estimated by the wet and dry corrosion test for 4 weeks. Figure 1 shows the corrosion test results for $16 \mathrm{Mn}$ alloy and carbon steel (SM). The extent of 


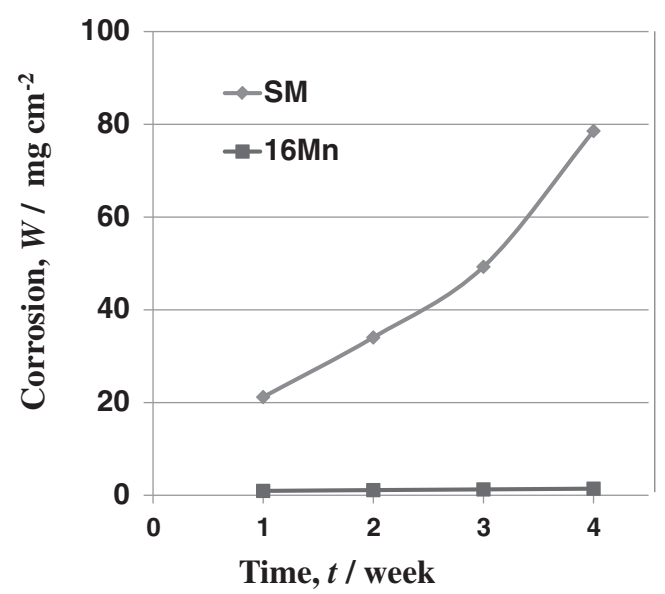

Fig. 1 Corrosion of $16 \mathrm{Mn}$ alloy and carbon steel (SM) after wet and dry corrosion test using 0.5 mass $\% \mathrm{NaCl}$.

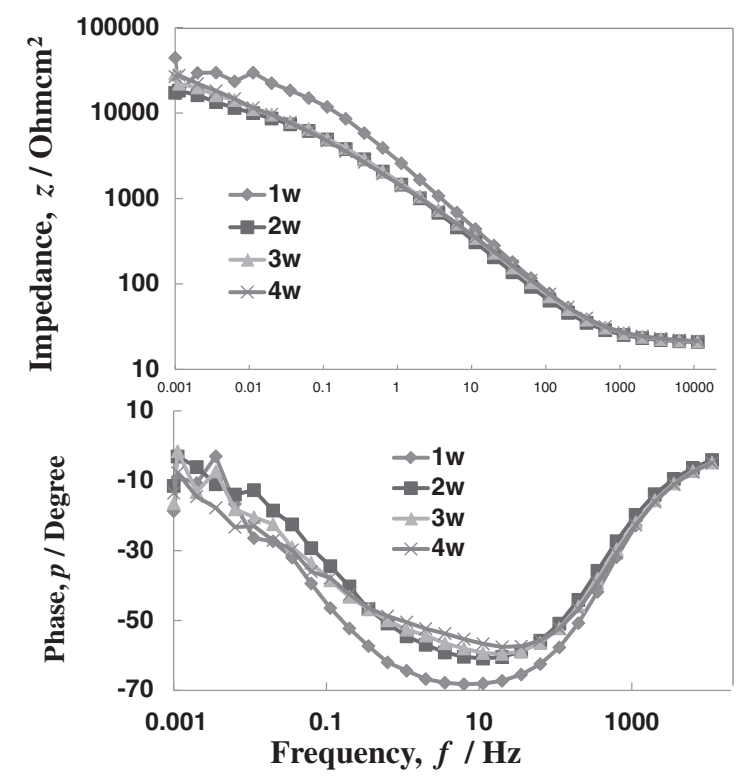

Fig. 2 Impedance spectra of $16 \mathrm{Mn}$ alloys after corrosion test.

corrosion was determined by the weight loss of samples following removal of the rust. The amount of corrosion of SM increases with time, and it is not saturated at 4 weeks. On the other hand, the amount of corrosion of $16 \mathrm{Mn}$ alloy is much less than that of SM after 4 weeks. In fact, 16Mn alloy could maintain a passive film on the surface after the corrosion test (like a stainless steel). Thus, $16 \mathrm{Mn}$ alloy exhibits excellent corrosion resistance in the corrosion test as compared to SM.

Figure 2 shows the results of EIS of $16 \mathrm{Mn}$ alloy after 4 weeks of the corrosion test. The two resistance components and one capacitance can be recognised in the spectrum. The impedance at higher frequency region $\left(Z_{\mathrm{h}}\right)$ is considered to be related to the resistance of the solution. On the other hand, as the impedance at lower frequency region $\left(R_{1}\right)$ is very high, it is considered to be the passive film resistance. Thus, the capacitance in the spectrum is considered the film capacitance. In this way, $16 \mathrm{Mn}$ alloy can maintain a passive film after a corrosion test, and shows high corrosion resistance.

Figure 3 displays the results of EIS of samples after the corrosion test, showing $Z_{1 \mathrm{mHz}}$ measured at $1 \mathrm{mHz}$ in Fig. 2 .

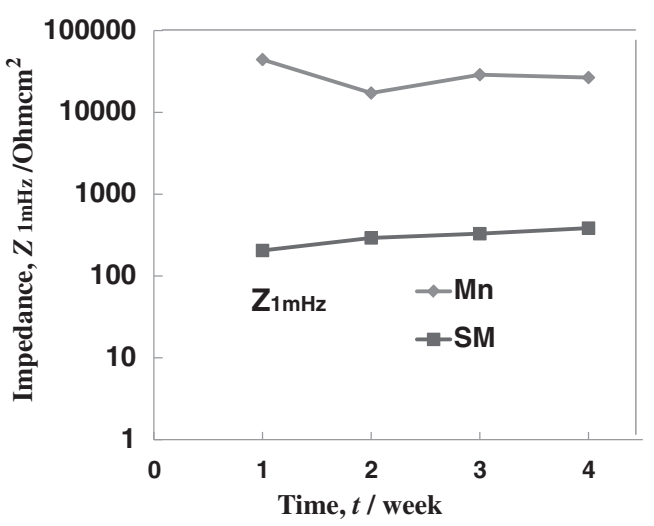

Fig. 3 Impedance values $\left(Z_{1 \mathrm{mHz}}\right)$ at $1 \mathrm{mHz}$ for $16 \mathrm{Mn}$ alloy and carbon steel (SM) after corrosion test.

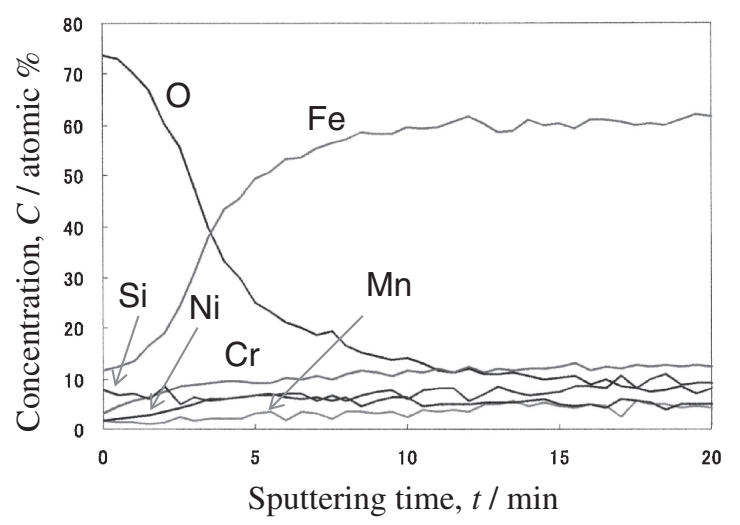

Fig. 4 Depth profile of elements by AES analysis for the passive film on 16 Mn alloy.

The $16 \mathrm{Mn}$ alloy shows much higher value of $Z_{1 \mathrm{mHz}}$ than that of SM each week. Since $Z_{1 \mathrm{mHz}}$ is assumed to be the corrosion resistance, this fact shows that $16 \mathrm{Mn}$ alloy has a higher resistance against corrosion than that of SM. In fact, because $16 \mathrm{Mn}$ alloy can maintain a passive film, a much higher resistance against corrosion (as compared to SM) is imparted to it.

\subsection{Surface analysis of the passive film on 16 Mn shape memory alloy}

In order to identify the corrosion-preventing mechanism of $16 \mathrm{Mn}$ alloy, the passive film was estimated by surface analysis. Figure 4 shows a depth profile of the elements in the passive film of $16 \mathrm{Mn}$ alloy obtained by AES after 4 weeks of the corrosion test. The concentrations (at\%) of Fe, $\mathrm{Mn}, \mathrm{Si}, \mathrm{Cr}, \mathrm{Ni}$ and Oxygen are shown. From the profile of Oxygen, the oxide film thickness is estimated almost $3 \mathrm{~nm}$ due to 5 min sputtering time. In this film, the concentrations of $\mathrm{Cr}$ and $\mathrm{Ni}$ are low at the surface, and they increase with the sputter time. Thus, $\mathrm{Cr}$ and $\mathrm{Ni}$ exist in inner of the film as much as that of the base metal. On the other hand, $\mathrm{Mn}$ and $\mathrm{Si}$ exist in the film, however, there is no special enrichment of these elements.

Figure 5 shows the results of XPS analysis of the elements in the passive film on $16 \mathrm{Mn}$ alloy. ${ }^{10)}$ The XPS spectra were acquired for the sample of $16 \mathrm{Mn}$ alloy with the take-off angle of 30, 60 and 90 degree. In the case of Fe 2p, the peak at 712 and $707 \mathrm{eV}$ are shown, which indicates that $\mathrm{Fe}$ is detected 

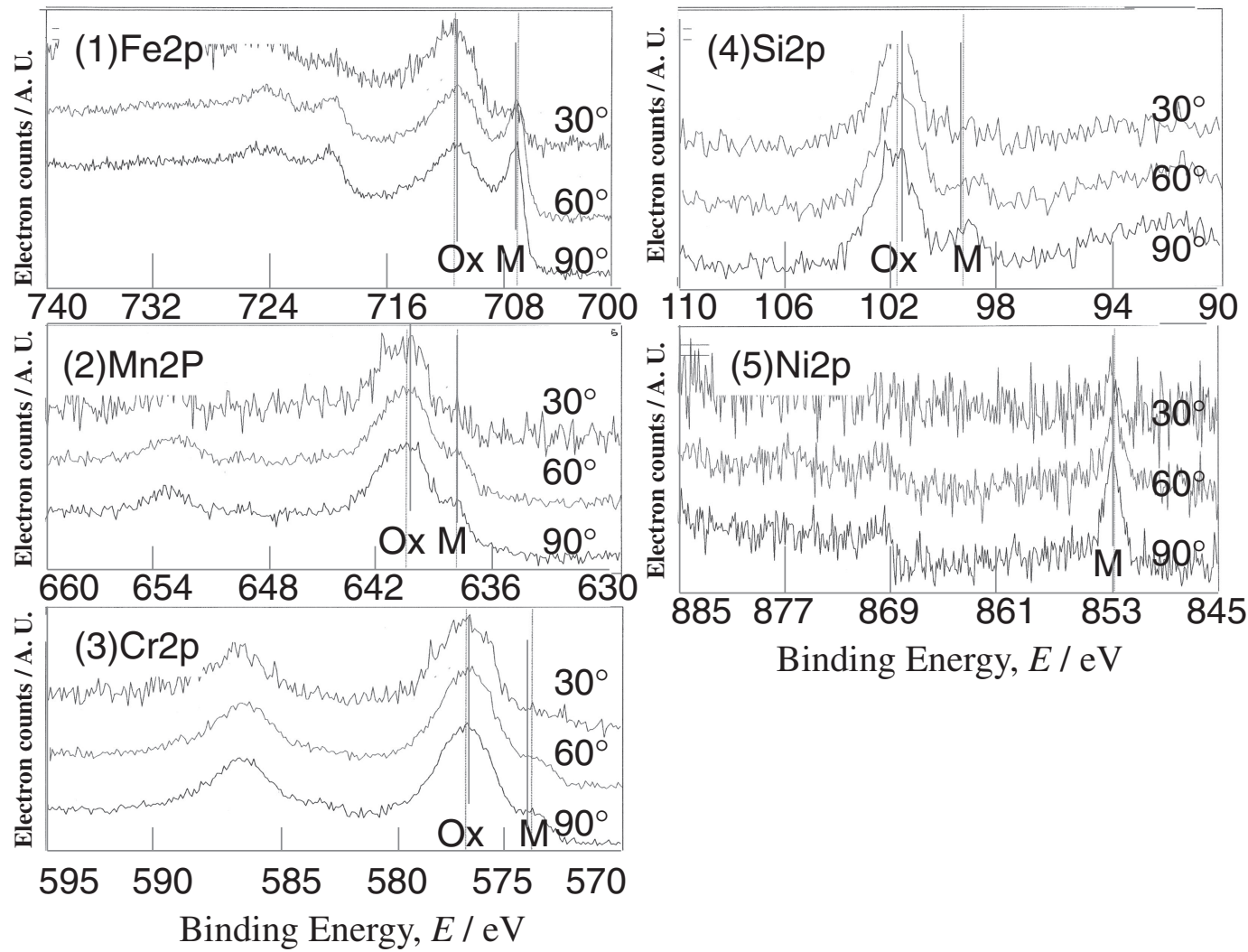

Binding Energy, $E / \mathrm{eV}$

Fig. 5 XPS analysis for the elements in the passive film on 16 Mn alloy; (1) Fe2p, (2) Mn2p, (3) Cr2p, (4) Si2p, (5) Ni2p.

both as the oxide and metal state. The peak of metal of $\mathrm{Fe}$ at $707 \mathrm{eV}$ is higher at the angle of 90 degree, indicating that $\mathrm{Fe}$ is detected as a metal in the inner of the film. In other word, Fe oxide exists mainly at the surface of the film of the alloy. For Mn $2 p$, there is a sharp peak at $640 \mathrm{eV}$ and a very small peak at $636 \mathrm{eV}$, which indicates that Mn exists mainly as an oxide state. This is almost the same as the case of Fe. For $\mathrm{Cr} 2 \mathrm{p}$, there is a sharp peak at $577 \mathrm{eV}$ and a very small peak at $573 \mathrm{eV}$, which indicates that $\mathrm{Cr}$ exists mainly as an oxide state. This is very similar to Si $2 p$, which has a sharp peak at $101 \mathrm{eV}$ and a very small peak at $99 \mathrm{eV}$. On the other hand, in the case of $\mathrm{Ni} 2 \mathrm{p}$, only the peak at $853 \mathrm{eV}$ is sharp, which indicates that $\mathrm{Ni}$ exists primarily as the metal state. Moreover, this metallic peak of $\mathrm{Ni}$ at $853 \mathrm{eV}$ is the highest at the angle of 90 degree, showing that $\mathrm{Ni}$ is enriched at the interface of the film and metal. From these results of XPS, it is found that the passive film contains $\mathrm{Fe}, \mathrm{Mn}, \mathrm{Cr}$ and $\mathrm{Si}$, and that $\mathrm{Ni}$ is enriched at the interface of the film and metal. However, it is not possible to verify the chemical state of each element in the film in this study using the peak shift of XPS spectrum.

In order to investigate the nano structure of the passive film on 16Mn alloy, an FIB-TEM analysis was conducted after the corrosion test. Figure 6 shows the FIB-TEM result for the passive film on $16 \mathrm{Mn}$ alloys. The spot numbers for the EDXS analysis are shown in the figure. From the contrast of the figure, it is possible to distinguish the position of the metal (1-5), the passive film (6-13) and the polymer (14). Thus the thickness of the passive film is estimated almost $2.5 \mathrm{~nm}$ from spot number 6 to 13 .

Figure 7 shows TEM-EDXS profiles for the elements in the passive film of $16 \mathrm{Mn}$ alloy. From the profile of Oxygen, the oxide film exists almost in spot number 7 to 14 . In the

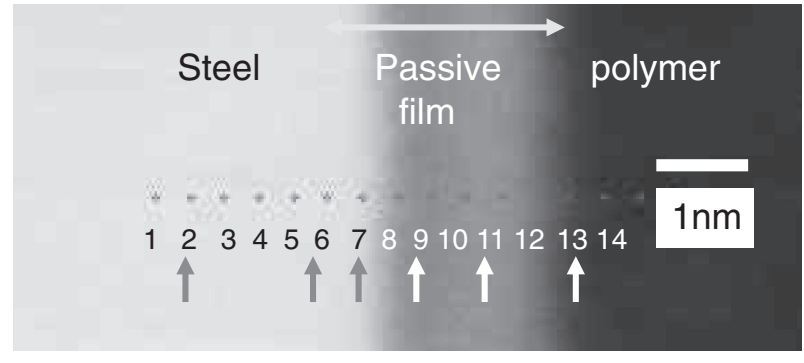

Fig. 6 FIB-TEM analysis for the passive film on $16 \mathrm{Mn}$ alloy.

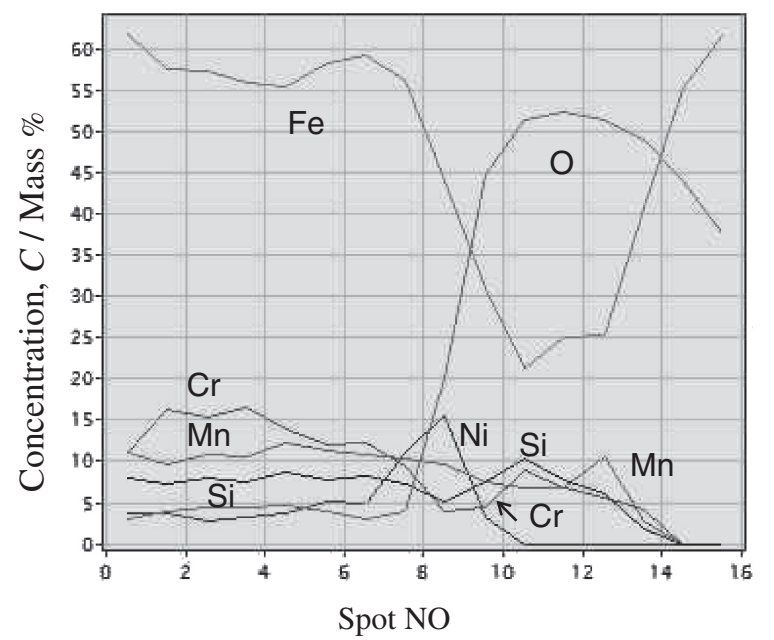

Fig. 7 TEM-EDXS results for the elements of the passive film of $16 \mathrm{Mn}$ alloy. Spot No is according to the point in Fig. 6.

passive film, Mn is enriched at the surface of the passive film. On the other hand, $\mathrm{Cr}$ and $\mathrm{Si}$ are enriched in the inner of the film. $\mathrm{Ni}$ is strongly enriched at the interface of the metal and 

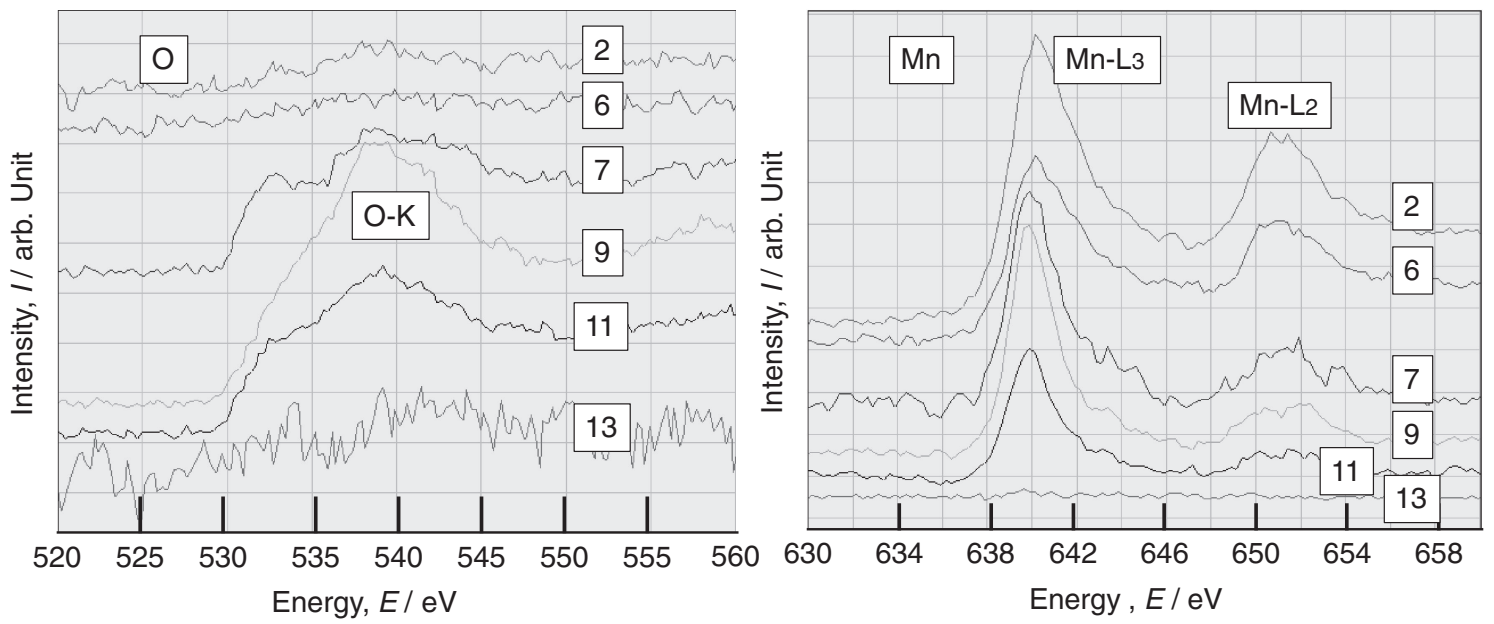

Fig. 8 TEM-EELS spectra of oxygen and Mn for the passive film of $16 \mathrm{Mn}$ alloy.
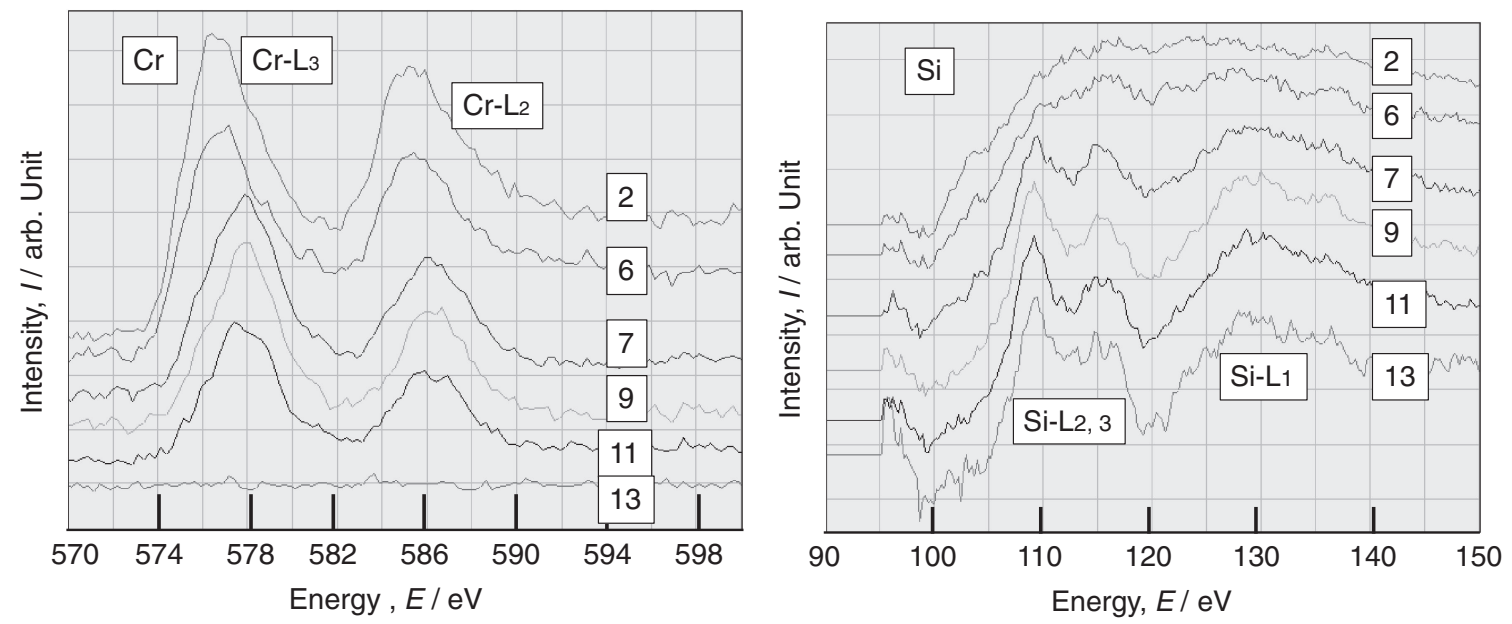

Fig. 9 TEM-EELS spectra of $\mathrm{Cr}$ and $\mathrm{Si}$ for the passive film of $16 \mathrm{Mn}$ alloy.

film. In this way, it is found that each element is enriched at the particular position in the passive film of $16 \mathrm{Mn}$ alloy. These results correlate well with those of XPS measurements in Fig. 5.

The chemical state in each element in the passive film was identified by using EELS, as shown in Figs. 8 to 10. The positions in EELS observation are the same as those in Fig. 6.

In Fig. 8, $O-k$ EELS spectra in the passive film of $16 \mathrm{Mn}$ alloy are shown in the spot of 7, 9, 11 and 13. Peaks at 532 and $538 \mathrm{eV}$ are shown in the spot of 7,9 and 11 . However, there is no peak in the spot 2 and 6 . Thus alloy is thought as the metal state in spot 2 and 6 . The peak at $532 \mathrm{eV}$ is a prepeak in the shape of the spectrum of $O-k$, which expresses the existence of the Oxygen that combines with the transient metals. ${ }^{11)}$ Thus, in spots 7, 9 and 11, the amount of Oxygen is thought high, which results in the passive film of alloy.

Mn-L EELS spectra are shown in Fig. 8, and can be placed into in two separate groups of $(2,6)$ and $(7,9,11)$ in terms of spot number. Peaks are observed at 640 and $650 \mathrm{eV}$ for spots 2 and 6 . On the other hand, Peaks at 639 and 651 are shown for spots 7,9 and 11. Thus, in the spectra of spots 7, 9 and 11, the top peak of $\mathrm{Mn}-\mathrm{L}_{3}$ are shifted $1 \mathrm{eV}$ lower, and that of $\mathrm{Mn}-\mathrm{L}_{2}$ are shifted $1 \mathrm{eV}$ higher. The shapes of $\mathrm{Mn}-\mathrm{L}_{3}$ are very sharply reduced from the top peak to higher energy direction for spots 7, 9 and 11, which is different from spots 2 and 6 . Moreover, the peak ratios of $\left(\mathrm{Mn}-\mathrm{L}_{2} / \mathrm{Mn}-\mathrm{L}_{3}\right)$ are lower for spots 7,9 and 11 as compared to spots 2 and 6. From these results, $\mathrm{Mn}$ is thought to exist in different state between spot $(2,6)$ and $(7,9,11)$. In the case of spot $2, \mathrm{Mn}$ exists in the metal state, per the result of Oxygen in Fig. 8. L. Laffont examined EELS spectra of $\mathrm{MnO}$ and $\mathrm{Mn}_{2} \mathrm{O}_{3} \cdot{ }^{12)}$ The spectrum of spot 6 is similar to $\mathrm{Mn}_{2} \mathrm{O}_{3}$ and those of spots 7, 9 and 11 are similar to $\mathrm{MnO}$ in his work. Besides, the chemical sift of the peak and peak ratios are able to explain by his work. Thus, $\mathrm{Mn}$ is thought to exist as $\mathrm{Mn}^{3+}$ oxide state in inner film of spot 6 , and $\mathrm{Mn}^{2+}$ oxide state in outer film of spots 7, 9 and 11.

Cr-L EELS spectra in the passive film of $16 \mathrm{Mn}$ alloy are shown in Fig. 9. Cr-L EELS spectra are similarly classified into two groups of $(2,6)$ and $(7,9,11)$ by spot number. The peaks at 576 and $585 \mathrm{eV}$ are shown for spots 2 and 6 . On the other hand, peaks at 578 and 586 are shown for spots 7, 9 and 11. Thus, for the spectra of spots 7, 9 and 11, the top peaks of $\mathrm{Cr}-\mathrm{L}_{3}$ are shifted $2 \mathrm{eV}$ higher, and those of $\mathrm{Cr}-\mathrm{L}_{2}$ are shifted $1 \mathrm{eV}$ higher. Moreover, the peak ratios of $\left(\mathrm{Cr}-\mathrm{L}_{2} / \mathrm{Cr}-\mathrm{L}_{3}\right)$ are lower for spots 7,9 and 11 as compared to spots 2 and 6 . From these results, $\mathrm{Cr}$ exists in different states in two groups. 

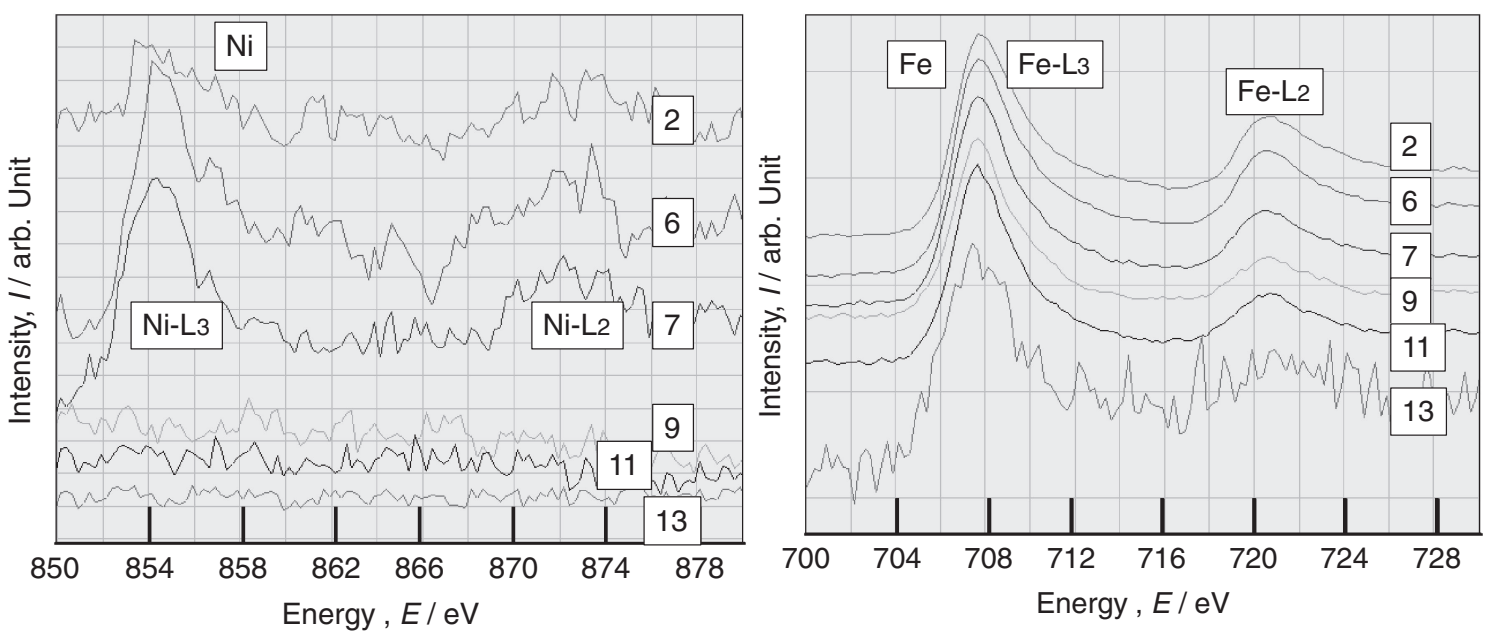

Fig. 10 TEM-EELS spectra of $\mathrm{Ni}$ and Fe for the passive film of $16 \mathrm{Mn}$ alloy.

In spot 2, Cr exists as a metal state from the result of Oxygen in Fig. 8. T. L. Daulton et al. summarized EELS spectra of Chromium oxides including $\mathrm{Cr}(\mathrm{II}) \mathrm{O}$ and $\mathrm{Cr}_{2} \mathrm{O}_{3} \cdot{ }^{13,14)}$ The spectrum of spot 6 is similar to $\mathrm{Cr}$ (II) $\mathrm{O}$ and those of spots 7 , 9 and 11 are similar to $\mathrm{Cr}_{2} \mathrm{O}_{3}$ in their papers. Besides, the chemical sift of the peak and peak ratios are able to explain by his work. Thus, $\mathrm{Cr}$ is thought to exist as $\mathrm{Cr}^{2+}$ oxide state in inner film of spot 6 , and $\mathrm{Cr}^{3+}$ oxide state in outer film of spot 7, 9 and 11 .

Si-L EELS spectra are shown in Fig. 9. These spectra are grouped in three by spot number of $(2),(6)$ and $(7,9,11)$. From the results of Oxygen in Fig. 8, the spectrum of the spot 2 is thought to demonstrate $\mathrm{Si}$ in the metal state. The spectrum of spot 6 has the absorbing edge at $101 \mathrm{eV}$, however, the spectra of spots 7,9 and 11 have it at $106 \mathrm{eV}$. In addition, the spectra of the spots 7,9 and 11 have sharp peaks at 110 and $118 \mathrm{eV}$. From these results, Si exists in a different state for 6 and $(7,9,11)$. In the previous paper, ${ }^{9,15)}$ EELS spectra of Si oxides were detected including standard chemicals of $\mathrm{Si}$ and $\mathrm{SiO}_{2}$. The spectra of spot 7, 9 and 11 are similar to that of $\mathrm{SiO}_{2}$. Thus, $\mathrm{Si}$ is thought to exist in $\mathrm{Si}^{4+}$ oxide state in outer film of spot 7,9 and 11. The spectrum of spot 6 is shown as the middle style between that of $\mathrm{SiO}_{2}$ and metal Si. As the shape of the spectra is reflected by the valence of $\mathrm{Si}$, the valence of $\mathrm{Si}$ of spot 6 is thought as 2 which is the middle of 0 and 4 . Thus, $\mathrm{Si}$ is thought to exist in $\mathrm{Si}^{2+}$ oxide state in inner film of spot 6 .

Ni-L EELS spectra of $16 \mathrm{Mn}$ alloy are shown in spots 2, 6 and 7 in Fig. 10. From results of Oxygen in Fig. 8, the spectrum of the spot 2 is thought to show that $\mathrm{Ni}$ is present in the metal state. Peaks at 854 and $872 \mathrm{eV}$ are shown for spots 6 and 7 . However, there is no peak detected for spots 9 and 11 . Thus $\mathrm{Ni}$ is enriched only at the interface of the film and metal, and there is no $\mathrm{Ni}$ in outer region of the passive film.

Fe-L EELS spectra are shown in the two groups of $(2,6)$ and $(7,9,11)$ by spot number. Peaks at 708 and $721 \mathrm{eV}$ are present for spots 2 and 6, while peaks at 707 and 720 are shown for spots 7, 9 and 11. Thus, the top peak of Fe- $\mathrm{L}_{3}$ and $\mathrm{Fe}-\mathrm{L}_{2}$ are shifted $1 \mathrm{eV}$ lower for the latter group. Moreover, the peak ratio $\left(\mathrm{Fe}-\mathrm{L}_{2} / \mathrm{Fe}-\mathrm{L}_{3}\right)$ is lower for spots 7,9 and 11 as compared to spots 2 and 6 . From these results, Fe also exists in a different state in spots $(2,6)$ and $(7,9,11)$. For spot 2 , Fe exists in a metal state from the result of Oxygen in Fig. 8. $\mathrm{H}$. Tan et al. examined the EELS spectra of Iron oxides including $\mathrm{Fe}(\mathrm{II}) \mathrm{O}$ and $\mathrm{Fe}_{2} \mathrm{O}_{3}{ }^{14}$ ) The spectrum of spot 6 is similar to that of $\mathrm{Fe}$ (II) O. Thus, $\mathrm{Fe}$ is thought to exist mainly as $\mathrm{Fe}^{2+}$ oxide state in inner film of spot 6 . On the other hand, the spectra of $\operatorname{spot}(7,9,11)$ are similar to that of $\mathrm{Fe}_{2} \mathrm{O}_{3}$. Thus $\mathrm{Fe}$ is thought to exist mainly as $\mathrm{Fe}^{3+}$ oxide state in outer film of $\operatorname{spot}(7,9,11)$.

In this way, although it needs more work to identify precisely, the chemical state of each element in the passive film of $16 \mathrm{Mn}$ ally are examined in this study.

\subsection{Nano structure of the passive film of 16 Mn shape memory alloy}

In the wet and dry corrosion test, $16 \mathrm{Mn}$ alloy showed much higher corrosion resistance than SM. Moreover, in EIS measurements, $16 \mathrm{Mn}$ alloy had much larger value of $Z_{1 \mathrm{mHz}}$ than that of SM after corrosion test. The primary reason for these was considered that the passive film of $16 \mathrm{Mn}$ alloy was maintained during the corrosion test, and could show high corrosion resistance.

TEM-EELS measurements were conducted to identify the nano structure of the passive film on $16 \mathrm{Mn}$ alloy. Figure 11 is a schematic diagram which shows the results of the TEM measurements. The passive film consists of 2 layers of a $\mathrm{Cr}-$ $\mathrm{Si}$ rich in inner and Mn-rich outer layer. Besides, the interface between the metal and film is enriched by Ni. The chemical state of each element is changing from the inner to outer layer. The chemical states are supposed as $\mathrm{Mn}^{3+}, \mathrm{Cr}^{2+}, \mathrm{Si}^{2+}$ and $\mathrm{Fe}^{2+}$ in inner layer, and $\mathrm{Mn}^{2+}, \mathrm{Cr}^{3+}, \mathrm{Si}^{4+}$ and $\mathrm{Fe}^{3+}$ in inner layer. Only $\mathrm{Mn}$ shows higher valence in inner layer than outer one. Maybe the inner or outer layer has another crystal structure, and each structure contains the suitable valence of $\mathrm{Mn}$. However, it needs more investigation to demonstrate this matter.

Thus, for the inner layer, the film is thought to contain mainly $\mathrm{Cr}^{2+}$ and $\mathrm{Si}^{2+}$ in Fe oxides. On the other hand, for the outer layer, the film is thought to contain mainly $\mathrm{Mn}^{2+}$ in $\mathrm{Fe}$ oxides. As the corrosion resistance of $16 \mathrm{Mn}$ alloy is thought to depend on the inner layer of the passive film, $\mathrm{Cr}$ and $\mathrm{Si}$ are 


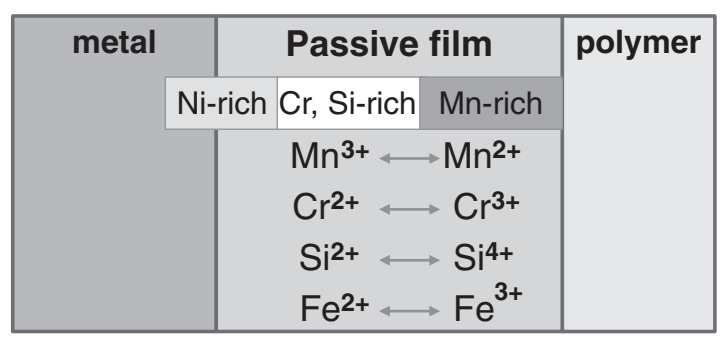

Fig. 11 Schematic diagram for the passive film of $16 \mathrm{Mn}$ alloy.

identified as the effective elements. Moreover, Ni and Mn are thought to support the passive film by forming an enrichment in the interface and outer layer, respectively. In this way, 16 Mn alloy can maintain the passive film composed of effective elements in the wet and dry environment. Thus, $16 \mathrm{Mn}$ alloy is able to have high corrosion resistance in the atmosphere containing Chloride ions.

\section{Conclusions}

A Fe-Mn-Si-Cr-Ni shape memory (16 Mn) alloy showed much higher corrosion resistance than carbon steel (SM) in the wet and dry corrosion test. Moreover, in EIS measurement, $16 \mathrm{Mn}$ alloy had a much larger value of corrosion resistance $\left(Z_{1 \mathrm{mHz}}\right)$ by forming the passive film as compared to SM after corrosion test. In AES and XPS analysis, the passive film of $16 \mathrm{Mn}$ alloy was shown to contain $\mathrm{Fe}, \mathrm{Mn}, \mathrm{Cr}$, $\mathrm{Si}$ and Ni. Based on TEM-EELS, the passive film consisted of 2 layers of $\mathrm{Cr}-\mathrm{Si}\left(\mathrm{Cr}^{2+}\right.$ and $\left.\mathrm{Si}^{2+}\right)$ enriched in inner and $\mathrm{Mn}$ $\left(\mathrm{Mn}^{2+}\right)$ enriched outer layer of $\mathrm{Fe}$ oxide. In addition, the interface between the metal and film was enriched with $\mathrm{Ni}$. It was found that $16 \mathrm{Mn}$ alloy could maintain the passive film composed of effective elements in the wet and dry environment.

\section{Acknowledgement}

The author thanks Mr T. Maruyama and Y. Chiba who prepared the sample and Dr T. Sawaguchi and Dr K. Tsuzaki for advices concerning the shape memory alloy used in this study.

\section{REFERENCES}

1) L. C. Chang and T. A. Read: Trans. Am. Inst. Min. Metall. Pet. Eng. 189 (1951) 47-54.

2) S. Miyazaki and K. Otsuka: ISIJ Int. 29 (1989) 353-377.

3) K. Otsuka, H. Sakamoto and K. Shimizu: Acta Metall. 27 (1979) 585601.

4) A. Sato, E. Chishima, K. Soma and T. Mori: Acta Metall. 30 (1982) 1177-1183.

5) A. Sato and T. Mori: Sci. Eng. A 146 (1991) 197-204.

6) H. Otsuka, H. Yamada, T. Maruyama, H. Tanahashi, S. Matsuda and M. Murakami: ISIJ Int. 30 (1990) 674-679.

7) H. Fukai, S. Suzuki, N. Masashi, S. Hanada, T. Maruyama, H. Kubo and Y. Waseda: Mater. Trans. 46 (2005) 1745-1748.

8) T. Nishimura, H. Katayama, K. Noda and T. Kodama: Corrosion 56 (2000) 935-941.

9) T. Nishimura: Corros. Sci. 52 (2010) 3609-3614.

10) J. F. Moulder, W. F. Strickle, P. E. Sobol and K. D. Bombem: Handbook of X-ray Photoelectron Spectroscopy, (Perkin-Elmer Corp., 1992).

11) H. Kurata, E. Lefevre, C. Colliex and R. Brydson: Phys. Rev. B 47 (1993) 13763-13768.

12) L. Laffont and P. Gibot: Mater. Charact. 61 (2010) 1268-1273.

13) T. L. Daulton and B. Little: Ultramicroscopy 106 (2006) 561-573.

14) H. Tan, J. Verbeeck, A. Abakumov and G. Van Tendeloo: Ultramicroscopy 116 (2012) 24-33.

15) T. Nishimura: Mater. Trans. 48 (2007) 1438-1443. 